\title{
Doxorubicin Activates Ryanodine Receptors in Rat Lymphatic Muscle Cells to Attenuate Rhythmic Contractions and Lymph Flow ${ }^{\text {S }}$
}

\author{
Amanda J. Stolarz, Mustafa Sarimollaoglu, John C. Marecki, Terry W. Fletcher, \\ Ekaterina I. Galanzha, Sung W. Rhee, Vladimir P. Zharov, V. Suzanne Klimberg, \\ and Nancy J. Rusch
}

\begin{abstract}
Department of Pharmacology and Toxicology, College of Medicine (A.J.S., T.W.F., S.W.R., N.J.R.) and Department of Biochemistry and Molecular Biology, College of Medicine (J.C.M.), Arkansas Nanomedicine Center, College of Medicine (M.S., V.P.Z.), Department of Pharmaceutical Sciences, College of Pharmacy (A.J.S.), and Laboratory of Lymphatic Research, Diagnosis and Therapy (E.I.G.), University of Arkansas for Medical Sciences, Little Rock, Arkansas; Division of Surgical Oncology, Department of Surgery, University of Texas Medical Branch, Galveston, Texas, and MD Anderson Cancer Center Houston, Texas (V.S.K.)
\end{abstract}

Received February 22, 2019; accepted August 9, 2019

\begin{abstract}
Doxorubicin is a risk factor for secondary lymphedema in cancer patients exposed to surgery or radiation. The risk is presumed to relate to its cytotoxicity. However, the present study provides initial evidence that doxorubicin directly inhibits lymph flow and this action appears distinct from its cytotoxic activity. We used real-time edge detection to track diameter changes in isolated rat mesenteric lymph vessels. Doxorubicin $(0.5-20 \mu \mathrm{mol} / \mathrm{l})$ progressively constricted lymph vessels and inhibited rhythmic contractions, reducing flow to $24.2 \% \pm 7.7 \%$ of baseline. The inhibition of rhythmic contractions by doxorubicin paralleled a tonic rise in cytosolic $\mathrm{Ca}^{2+}$ concentration in lymphatic muscle cells, which was prevented by pharmacological antagonism of ryanodine receptors. Washout of doxorubicin partially restored lymph vessel contractions, implying a pharmacological effect. Subsequently, high-speed optical imaging was used to assess the effect of doxorubicin on rat mesenteric lymph flow in vivo. Superfusion of doxorubicin $(0.05-10 \mu \mathrm{mol} / \mathrm{l})$ maximally reduced volumetric lymph flow to $34 \% \pm 11.6 \%$ of baseline. Likewise, doxorubicin $(10 \mathrm{mg} / \mathrm{kg})$ administered intravenously to establish clinically achievable plasma concentrations also maximally reduced volumetric lymph flow to $40.3 \% \pm 6.0 \%$ of initial values.
\end{abstract}

Our findings reveal that doxorubicin at plasma concentrations achieved during chemotherapy opens ryanodine receptors to induce "calcium leak" from the sarcoplasmic reticulum in lymphatic muscle cells and reduces lymph flow, an event linked to lymph vessel damage and the development of lymphedema. These results infer that pharmacological block of ryanodine receptors in lymphatic smooth muscle cells may mitigate secondary lymphedema in cancer patients subjected to doxorubicin chemotherapy.

\section{SIGNIFICANCE STATEMENT}

Doxorubicin directly inhibits the rhythmic contractions of collecting lymph vessels and reduces lymph flow as a possible mechanism of secondary lymphedema, which is associated with the administration of anthracycline-based chemotherapy. The inhibitory effects of doxorubicin on rhythmic contractions and flow in isolated lymph vessels were prevented by pharmacological block of ryanodine receptors, thereby identifying the ryanodine receptor family of proteins as potential therapeutic targets for the development of new antilymphedema medications.

\section{Introduction}

Intractable secondary lymphedema may result from radiation therapy and surgery to minimize or eliminate malignancies, particularly after excision of sentinel or axillary lymph nodes. Most visible is secondary lymphedema of the arm, which affects 5 million women in the United States and is a recognized complication of radiation and surgery for breast cancer (Norman et al., 2010; Ahmed et al., 2011; Bevilacqua et al., 2012; Shah et al., 2012b; Rivere and Klimberg, 2018). Secondary lymphedema also occurs at other sites of tumor resection, for example, in lower limbs as a complication of inguinal or ileoinguinal lymphadenectomy to stage malignant melanoma (Söderman et al., 2016). It also is diagnosed in the abdomen, genitals, and other anatomic sites after lymph flow is compromised by surgical interventions or local radiation (Cormier et al., 2010; Shaitelman et al., 2015). The static and excessive interstitial fluid that characterizes secondary lymphedema is associated with grave medical complications, including lymphangitis, cellulitis, ulcers, and malignant lymphangiosarcomas (Ridner et al., 2012; Sharma and Schwartz, 2012; Söderman et al., 2016). Additionally,

ABBREVIATIONS: 2-APB, 2-Aminoethoxydiphenyl borate; $\left[\mathrm{Ca}_{\mathrm{i}}^{2+}\right]$, cytosolic free calcium; $\mathrm{Ca}_{\mathrm{v}} 1.2$, L-type $\mathrm{Ca}^{2+}$ channel; DOX, doxorubicin; EDD, end diastolic diameter; ESD, end systolic diameter; HPLC, high-performance liquid chromatography; IP ${ }_{3}$, inositol trisphosphate; PSS, physiologic salt solution; RYR, ryanodine receptor; SAL, saline. 

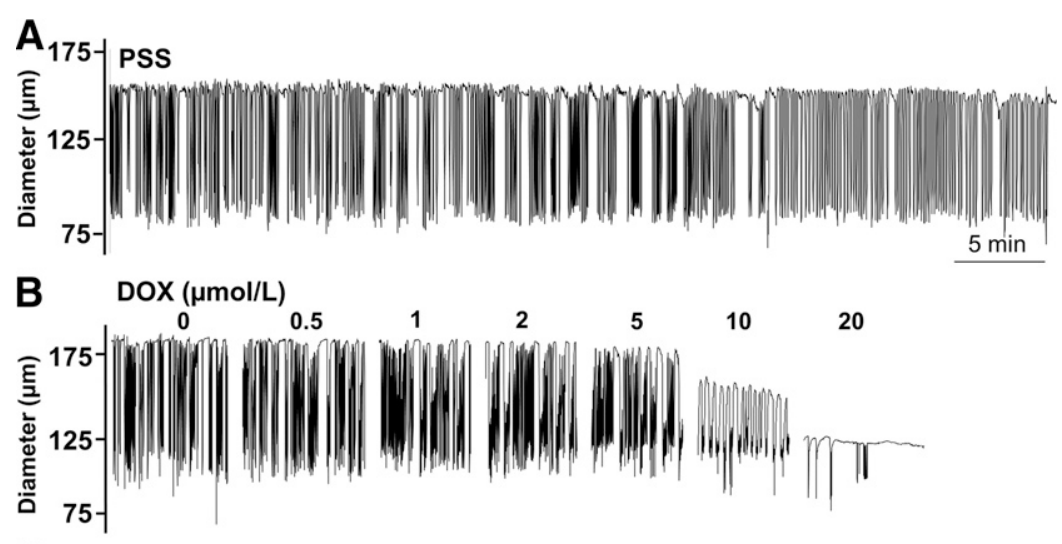

Fig. 1. DOX inhibits lymphatic contractions in isolated rat mesenteric lymph vessels. (A) Rhythmic contractions of a control lymph vessel in physiologic salt solution. (B) In another lymph vessel, increasing concentrations of DOX $(0.5-20 \mu \mathrm{mol} / \mathrm{l})$ progressively inhibited rhythmic contractions and reduced end-diastolic diameter. (C) A subset of lymph vessels exposed to DOX were returned to drug-free PSS, which reversed the inhibitory effect of DOX on rhythmic contractions.
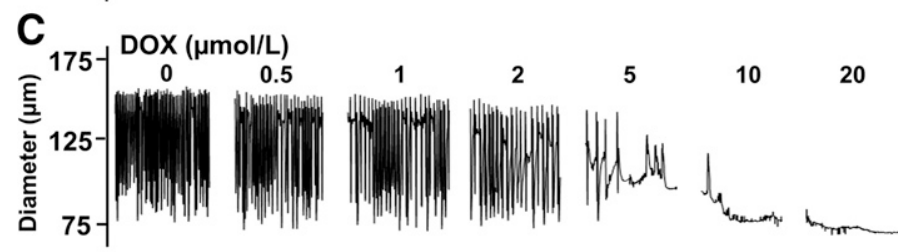

PSS

lymphedema compromises quality of life by inflicting permanent pain and disfigurement (Cormier et al., 2010; Shah and Vicini, 2011; Shah et al., 2012a). Moreover, the treatment of secondary lymphedema is limited to approaches that physically alter fluid forces, including compressive bandages, pneumatic pumps, lymphatic massage, and less often, reconstructive surgery to anastomose lymph vessels to themselves or to veins (Shah et al., 2012a; Shaitelman et al., 2015; Tummel et al., 2017).

In patients subjected to radiation and/or surgery, anthracycline chemotherapeutic agents, particularly doxorubicin (DOX), increase the risk of secondary lymphedema by 4 - to 5-fold (Norman et al., 2010; Ahmed et al., 2011; Bevilacqua et al., 2012). The mechanism by which DOX causes this offtarget toxicity is unknown, but the prevailing assumption is that the antimitotic and cytotoxic activities of DOX acutely injure the lymphatic circulation, resulting in lymphostasis and exposure of the lymphatic circulation to

This work has been partially presented in a dissertation and meeting abstracts: Stolarz AJ (2016), Doxorubicin Inhibition of Lymphatic Function and Prevention by Dantrolene. Doctoral dissertation, University of Arkansas for Medical Sciences, Little Rock, AR.

Stolarz AJ, Pathan A, Versluis R, Fletcher TW, Stimers JR, Galanzha EI, Zharov VP, Rusch NJ. Doxorubicin inhibition of lymphatic function is mediated by ryanodine receptors and prevented by dantrolene. Experimental Biology 2015, FASEB Pharmacology Vol 29 (1) supplement, Abstract 785.12.

Stolarz AJ, Fletcher TW, Marecki JC, Sarimollaoglu M, Galanzha EI, Zharov VP, Klimberg VS, Rusch NJ. Doxorubicin acutely inhibits lymph flow in rat mesenteric lymph vessels. Experimental Biology 2016, FASEB Pharmacology Vol 30 (1) supplement, Abstract 1201.2.

Research was supported by the National Institutes of Health [R21 CA187325 (N.J.R.), R01 CA131164 (V.Z.), R01 EB017217 (V.Z.), and R21 EB022698 (E.I.G.)] and from the National Science Foundation [OIA 1457888 (V.Z.) and DBI 1556068 (V.Z.)]. Other sources of funding included a Pharmaceutical Research and Manufacturers of America (PhRMA) Predoctoral Fellowship (A.J.S.), Rho Chi American Foundation for Pharmaceutical Education (AFPE) First Year Graduate Fellowship (A.J.S.), pilot grant from the UAMS Translational Research Institute (V.P.Z.), UAMS College of Medicine Pilot Grant (N.J.R.), and pilot grant from the Center for Studies of Host Response to Cancer Therapy through Center of Biomedical Research Excellence Award P20GM109005 (A.J.S.).

https://doi.org/10.1124/jpet.119.257592.

S This article has supplemental material available at jpet.aspetjournals.org. excessive intravascular pressure. The insult of high lymphostatic pressure permanently damages the endothelial cells, muscle cells, and valves that compose the delicate lymph vessels (Ji and Kato, 2001). However, in addition to structural damage, it is possible that DOX directly suppresses the functional ability of the lymphatic circulation to propel lymph fluid containing protein, lipids, lymphocytes, and other cells from peripheral interstitial spaces to the central venous ducts to maintain fluid homeostasis (Schmid-Schönbein, 1990; Choi et al., 2012; Hansen et al., 2015).

In this regard, the distal-to-proximal transport of lymph fluid is accomplished under normal conditions by spontaneous contractions of lymphatic muscle cells composing the walls of collecting lymph vessels. Spontaneous depolarization of the lymphatic muscle cells opens voltage-gated L-type $\mathrm{Ca}^{2+}$ $\left(\mathrm{Ca}_{\mathrm{v}} 1.2\right)$ channels, which mediate an influx of $\mathrm{Ca}^{2+}$ to activate the contractile proteins that support rhythmic contractile motion (Gashev, 2002; Imtiaz et al., 2007; Dougherty et al., 2008; Davis et al., 2011; Nipper and Dixon, 2011). The transient rise in cytosolic free $\mathrm{Ca}^{2+}\left(\left[\mathrm{Ca}_{\mathrm{i}}^{2+}\right]\right)$ also releases intracellular $\mathrm{Ca}^{2+}$ stores by activating inositol trisphosphate $\left(\mathrm{IP}_{3}\right)$ receptors in the sarcoplasmic reticulum $(\mathrm{SR})$ to further promote $\mathrm{Ca}^{2+}$ signaling and contraction (Imtiaz et al., 2007). In contrast, the contribution to $\mathrm{Ca}^{2+}$ signaling by ryanodine receptors (RYRs), the other main family of $\mathrm{Ca}^{2+}$ release channels in the SR, is regarded as minimal (Atchison et al., 1998; Zhao and van Helden, 2003). Notably, it is well established that DOX interferes with a number of proteins involved in $\mathrm{Ca}^{2+}$ signaling in striated muscle, including cardiomyocytes and skeletal muscle cells (Renu et al., 2018). In particular, several reports indicate that DOX can activate $\mathrm{Ca}_{\mathrm{v}} 1.2$ channels and RYRs, and inhibit the $\mathrm{Ca}^{2+}$-ATPase (SERCA) pump of the sarco/endoplasmic reticulum to cause protracted elevation of $\left[\mathrm{Ca}_{\mathrm{i}}^{2+}\right.$ ] (Abramson et al., 1988; Pessah et al., 1990; Keung et al., 1991; Kim et al., 2006; Hanna et al., 2014). However, to our knowledge, the direct effects of DOX on $\mathrm{Ca}^{2+}$ signaling and contraction of lymphatic muscle cells, and the impact of DOX on lymph flow in vivo have not been described. 

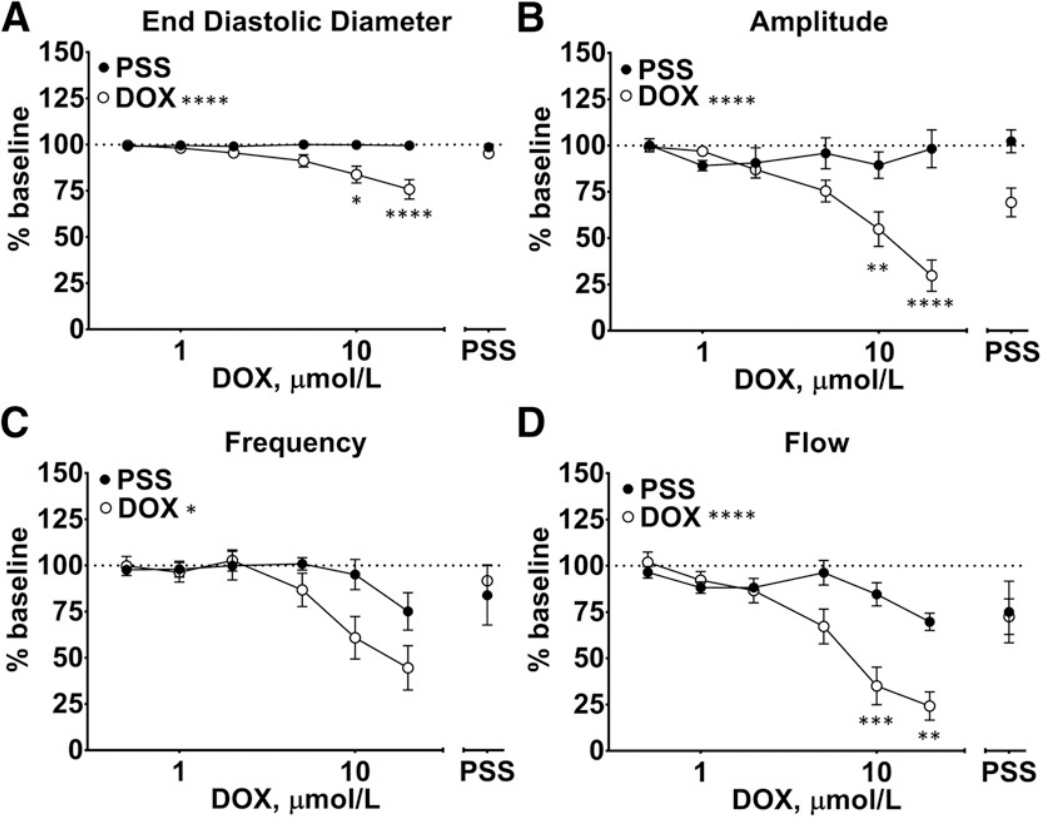

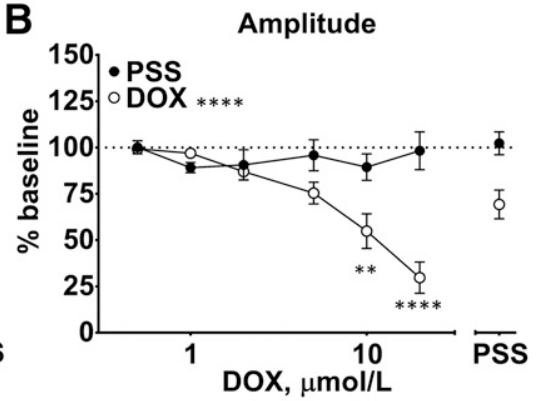

Fig. 2. DOX reduces end-diastolic diameter, contraction frequency and amplitude, and calculated flow in isolated rat mesenteric lymph vessels. Lymph vessels were exposed either to drug-free PSS (control) or to increasing concentrations of DOX $(0.5-20 \mu \mathrm{mol} / \mathrm{l})$. Data from lymph vessels exposed to DOX and control vessels exposed to PSS were compared at the same time point for statistical analysis. In 12 lymph vessels, (A) DOX progressively decreased EDD and (B) the amplitude of rhythmic contractions $(n=12)$, and these effects were partially reversed after washout of DOX $(n=8)$. Likewise, (C) contraction frequency and (D) calculated flow were significantly reduced by DOX compared with PSS control $(n=12)$, and these effects also were at least partially reversed after washout of DOX $(n=8)$. Data reported as mean \pm S.E.M. analyzed using two-way ANOVA with Holm-Sidak post-test $(n=12 ; * P<0.05$ $* * P<0.01 ; * * * P<0.001 ; * * * P<0.0001)$
Considering that lymph transport is highly dependent on tightly regulated $\mathrm{Ca}^{2+}$ signaling, the protection of the lymphatic circulation from DOX-induced disruptions in $\mathrm{Ca}^{2+}$ signaling may represent a strategy to minimize the incidence of secondary lymphedema and its lasting complications. Here, we used isolated rat mesenteric lymph vessels to determine whether DOX disrupts the phasic $\mathrm{Ca}^{2+}$ signaling that underlies the rhythmic contractions of lymph vessels. Parallel studies used in-vivo optical imaging to determine whether clinically achievable plasma concentrations of DOX impair lymphatic drainage in the intact lymphatic circulation, an event associated with long-term injury to lymph vessels and secondary lymphedema (Ji and Kato, 2001). Our findings that pharmacological block of RYRs protects lymph vessels from the detrimental actions of DOX with minimal effects on normal $\mathrm{Ca}^{2+}$ signaling suggests a possible therapeutic target to reduce the incidence of secondary lymphedema in cancer patients subjected to doxorubicin chemotherapy.

\section{Methods}

Animals. Rat mesenteric lymph vessels were obtained from 8- to 12-week-old male Sprague-Dawley rats purchased from Harlan (Indianapolis, IN) for ex vivo studies. Animals were deeply anesthetized using $3.5 \%$ isoflurane with $1.5 \mathrm{l} / \mathrm{min}$ oxygen and euthanized by decapitation. In vivo studies used younger (5- to 7-week-old) male
Sprague-Dawley rats from the same commercial vendor to minimize interference from mesenteric fat during optical imaging of in situ mesenteric lymph vessels. After optical imaging, the anesthetized animals were euthanized by exsanguination from cardiac puncture. All procedures were carried out in accordance with the Guide for the Care and Use of Laboratory Animals as adopted and promulgated by the U.S. National Institutes of Health and approved in animal use protocol no. 3672 by the Institutional Animal Care and Use Committee at the University of Arkansas for Medical Sciences.

Diameter and Estimated Flow in Isolated Lymph Vessels. Diameter responses to DOX (Pfizer, UAMS Hospital Pharmacy, Little Rock, AR) and ryanodine (1329; Tocris, Minneapolis, MN) were evaluated in second-order mesenteric lymph vessels with outer diameters of $100-200 \mu \mathrm{m}$. The vessels were dissected from the mesenteric arcade, which was secured in a silicone-lined culture dish containing physiologic salt solution (PSS) composed of (in millimolars per liter): $119 \mathrm{NaCl}, 24 \mathrm{NaHCO}_{3}, 1.17 \mathrm{NaH}_{2} \mathrm{PO}_{4}, 4.7 \mathrm{KCl}, 1.17 \mathrm{MgSO}_{4}$, 5.5 glucose, 0.026 EDTA, $1.6 \mathrm{CaCl}_{2}$; bubbled with $7 \% \mathrm{CO}_{2}$ to maintain $\mathrm{pH}$ 7.4. Subsequently, single lymph vessels were cannulated using borosilicate glass micropipettes (outer diameter, $1.2 \mathrm{~mm}$; inner diameter, $0.68 \mathrm{~mm}$ ) pulled to achieve tip diameters of 75-100 $\mu \mathrm{m}$ (GCP75-100; Living Systems Instrumentation, Burlington, VT), and then pressurized at $4-5 \mathrm{~mm} \mathrm{Hg}$ for 45 minutes in a perfusion chamber (Living Systems Instrumentation) containing PSS until rhythmic contractions were stable. Diameter measurements in response to $\operatorname{DOX}(0.5-20 \mu \mathrm{mol} / \mathrm{l})$ followed by drug washout for 10 minutes in a subset of vessels were acquired using video-microscopy equipped with edge detection software (IonOptix Corporation, Westwood, MA)

TABLE 1

DOX reduces end-diastolic diameter, contraction frequency, and amplitude, and calculated flow in isolated rat mesenteric lymph vessels Exposure of lymph vessels to increasing concentrations of DOX $(0.5-20 \mu \mathrm{mol} / \mathrm{l})$ progressively decreased EDD, contraction frequency, amplitude, and calculated flow (*P $<0.05$; ${ }^{* *} P<0.01$; ${ }^{* * *} P<0.001$; $* * * * P<0.0001 ;$ mean \pm S.E.M., $\left.n=12\right)$. These effects were partially reversed after washout of DOX $(\dagger P<0.05 ;$ mean $\pm S . E . M$., $n=8)$.

\begin{tabular}{lcccc}
\hline DOX & EDD & Frequency & Amplitude & Flow \\
\hline$\mu M$ & & & $\%$ Baseline & \\
0.5 & $99.6 \pm 0.4$ & $99.7 \pm 5.2$ & $99.3 \pm 1.9$ & $101.9 \pm 5.5$ \\
1 & $98.1 \pm 0.8$ & $96.3 \pm 5.3$ & $96.9 \pm 2.4$ & $92.2 \pm 4.7$ \\
2 & $95.5 \pm 1.4$ & $102.7 \pm 5.7$ & $86.9 \pm 4.4$ & $86.6 \pm 6.5$ \\
5 & $91.2 \pm 3.3$ & $86.7 \pm 9.0$ & $75.4 \pm 5.9$ & $67.2 \pm 9.4$ \\
10 & $83.8 \pm 4.5^{*}$ & $60.9 \pm 11.5$ & $54.9 \pm 9.4^{* *}$ & $35.1 \pm 10.1^{* * * *}$ \\
20 & $75.8 \pm 5.3^{* * * *}$ & $44.6 \pm 12.0$ & $27.9 \pm 8.4^{* * * *}$ & $24.2 \pm 7.7^{* *}$ \\
Washout & $95.1 \pm 2.2$ & $91.7 \pm 8.5 \dagger$ & $69.3 \pm 7.8^{\dagger}$ & $75.5 \pm 9.6 \dagger$ \\
\hline
\end{tabular}



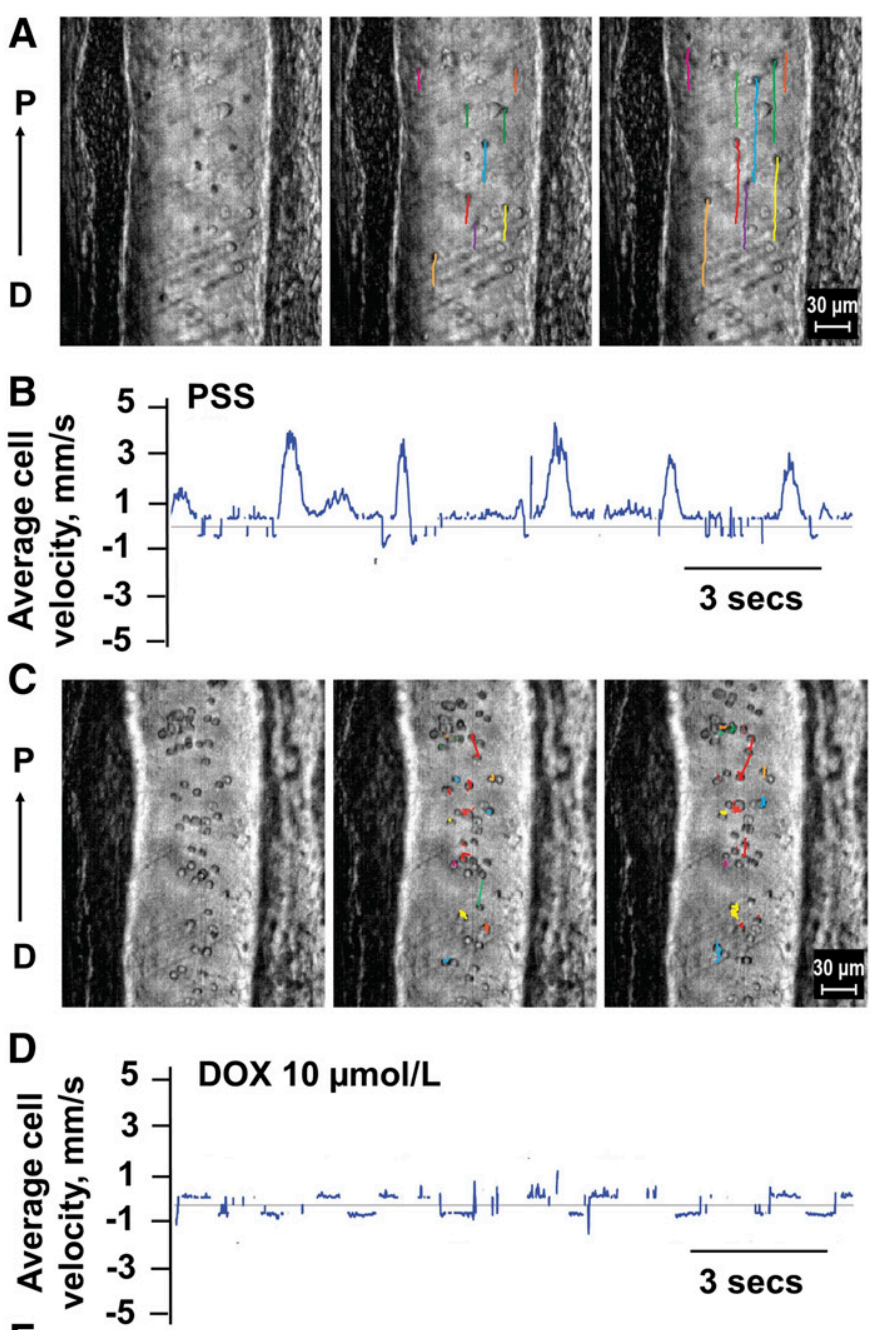

E

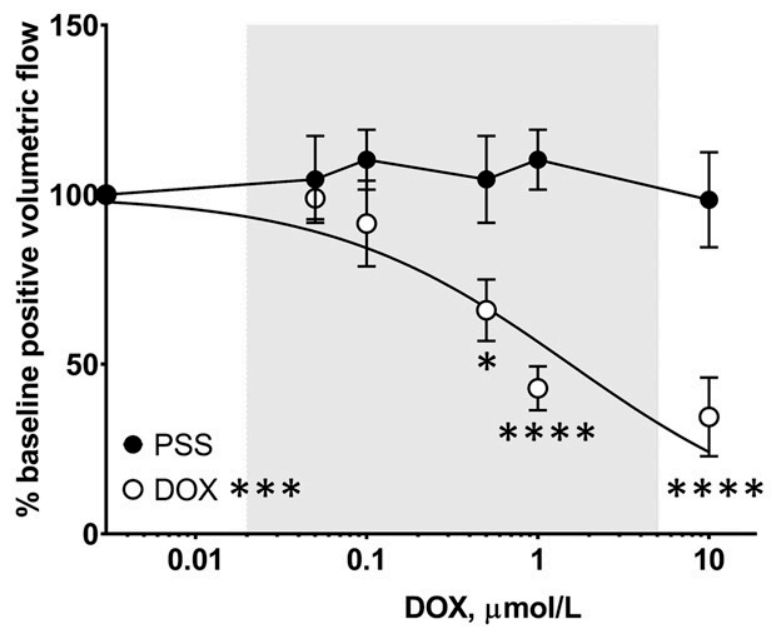

Fig. 3. Superfusion of DOX decreases volumetric lymph flow in rat mesenteric lymph vessels. (A) Prior to DOX superfusion, frame-by-frame cell tracking (300 frames/sec video capture) measures the distance traveled by a cell in lymph fluid as a function of time, which provides an estimate of cell velocity. Representative still images are shown in 10 frame intervals over the course of 20 frames (sampled every 67 milliseconds). Colored lines represent individual cell paths from initial frame. (B) Upward and downward deflections reflect average positive and negative cell velocities, respectively, in lymph vessels prior to superfusion of DOX. (C) Superfusion of DOX (10 $\mu \mathrm{mol} / \mathrm{l})$ decreased cell path lengths and (D) reduced average lymph cell velocity (seen as attenuated upward deflections) indicating the induction of "lymphostasis." (E) Increasing for online capture of outer diameter at a collection rate of $3 \mathrm{~Hz}$. Enddiastolic diameter (EDD), end-systolic diameter (ESD), and contraction amplitude and frequency at baseline during the last 5 minutes of each drug administration and after drug washout were analyzed by Origin 9.1 software (OriginLab Corporation, Northampton, MA). Flow per unit length $(1 \mu \mathrm{m})$ in single lymph vessels was calculated using the equation $\pi / 4\left(E D D^{2}-E S D^{2}\right) F$, where $E D D^{2}$ serves as a measure of the resting vessel cross-sectional area between contractions; $E S D^{2}$ serves as a measure of the vessel cross-sectional area during peak contraction; and $F$ indicates the frequency of rhythmic contractions. Accordingly, flow changes in isolated lymph vessels are relative values expressed as percent of flow under control conditions.

Lymph Flow In Vivo. Male rats were fasted overnight (access to water ad libitum) and anesthetized using $2.5 \%$ isoflurane in $1.5 \mathrm{l} / \mathrm{min}$ oxygen. A single mesenteric loop was exposed through a small midline incision and placed on a heated $\left(37-38^{\circ} \mathrm{C}\right)$ microscope stage equipped with a recirculating bath containing HEPES-PSS composed of (in millimolars per liter): $119 \mathrm{NaCl}, 4.7 \mathrm{KCl}, 1.17 \mathrm{MgSO}_{4}, 1.6 \mathrm{CaCl}_{2}, 24$ $\mathrm{NaHCO}_{3}, 0.026$ EDTA, $1.17 \mathrm{NaH}_{2} \mathrm{PO}_{4}, 5.5$ glucose, 5.8 HEPES; $\mathrm{pH}$ to 7.4 with $\mathrm{NaOH}$. The lymph vessel outer diameter was recorded as described earlier (Souza-Smith et al., 2011). Lymph flow was measured continuously using high speed in vivo flow cytometry and an inverted microscope (Olympus, Tokyo, Japan) equipped with a monochrome high-speed CMOS camera (model MV-D1024-160-CL8; Photonfocus AG, Lachen SZ, Switzerland) to acquire high-speed images of moving cells with minimum distortion at relatively high speeds ( $\leq 7 \mathrm{~mm} / \mathrm{s})$ (Galanzha et al., 2007a; Sarimollaoglu et al., 2018). Videos of lymph flow were then analyzed using custom software developed by the UAMS Nanomedicine Center. Details of the instrumentation and software used to calculate lymph flow were published recently by us (Sarimollaoglu et al., 2018). Briefly, lymph flow velocity initially was analyzed as bidirectional flow, whereby cell movement from distal to proximal (positive flow) is characterized as a positive deflection, and cell movement from proximal to distal (negative flow) is characterized as a negative deflection. Cell velocity and diameter measurements were used to calculate positive volumetric lymph flow. This innovative method for detection of moving cells in lymph vessels in vivo does not require fluorescent or infrared dyes and allows for continuous data acquisition rather than discrete measurements (Sarimollaoglu et al., 2018).

Using this in vivo preparation, baseline measurements of lymph vessel diameter and lymph flow were obtained for 20 minutes. Then DOX was either superfused over the mesenteric loop to tightly control the drug concentration, or rapidly infused into the tail vein using a 27gauge butterfly needle as a single dose $(10 \mathrm{mg} / \mathrm{kg})$ using a stock solution $(2 \mathrm{mg} / \mathrm{ml})$. The butterfly tubing was connected to a programmable NE-1000 syringe pump (Advanced Precision Instruments, Sparta, NJ) to infuse DOX at $1 \mathrm{ml} / \mathrm{min}$ to achieve the full $10-\mathrm{mg} / \mathrm{kg}$ dose. Infusion volume did not exceed $1.5 \mathrm{ml}$, which is approx. $10 \%$ of the total blood volume of an adult rat (Diehl et al., 2001). An equal volume of $0.9 \%$ injectable saline served as control. Subsequently, measurements of lymph vessel diameter and lymph flow were acquired continuously for 2 hours after administration of DOX.

Pharmacokinetic Studies. A separate pharmacokinetic study was conducted in five male rats following intravenous (i.v.) infusion of DOX $(10 \mathrm{mg} / \mathrm{kg})$ via the tail vein as described above. Serial blood samples were collected from the retro-orbital sinus of rats at 5, 15, 30, 60,120 , and 240 minutes after DOX infusion and stored in microcentrifuge tubes containing $4 \%$ sodium citrate at $-20^{\circ} \mathrm{C}$. Thawed

concentrations of DOX $(0.5-10 \mu \mathrm{mol} / \mathrm{l})$ decreased positive volumetric lymph flow $\left(\mathrm{IC}_{50}=1.54 \mu \mathrm{mol} / \mathrm{l}\right)$. Gray shading denotes clinically achievable plasma concentrations of DOX at $\leq 4$ hours after an intravenous push infusion. Data reported as mean \pm S.E.M. and analyzed using two-way ANOVA with Holm-Sidak post-test $(n=5$ and $6 ; * P<0.05 ; * * * P<0.001$; $* * * * P<0.0001)$ 


\section{TABLE 2}

Superfusion of DOX decreases volumetric lymph flow in rat mesenteric lymph vessels

Increasing concentrations of DOX $(0.5-10 \mu \mathrm{mol} / \mathrm{l})$ decreased positive volumetric lymph flow $(* P<0.05 ; * * * P<0.0001 ;$ mean \pm S.E.M., $n=5$ to 6$)$.

\begin{tabular}{lc}
\hline DOX & Positive Volumetric Flow \\
\hline$\mu M$ & $\%$ Baseline \\
0.05 & $98.9 \pm 5.1$ \\
0.01 & $91.5 \pm 10.3$ \\
0.5 & $65.9 \pm 9.1^{*}$ \\
1 & $42.9 \pm 6.5^{* * * *}$ \\
10 & $34.5 \pm 11.6^{* * * *}$ \\
\hline
\end{tabular}

samples were prepared and processed for high-performance liquid chromatography (HPLC) analysis to estimate DOX concentrations (Alvarez-Cedrón et al., 1999; Wei et al., 2008; Daeihamed et al., 2015). HPLC was performed using a Shimadzu LC-10ATVP (Shimadzu Scientific Instruments, Kyoto, Japan) equipped with a SIL-10ADVP autoinjector with a 50- $\mu$ l sample loop and a CTO-10ASVP column heater set to $35^{\circ} \mathrm{C}$. Compounds were detected by a SPD-M10AVP UV/visible diode array detector and RF-10AXL fluorescence detector using an excitation wavelength of $480 \mathrm{~nm}$ and emission wavelength of $560 \mathrm{~nm}$. The Shimadzu Class VP Version 7.4-SP1 software was used for system control, data acquisition, and chromatogram analysis. Doxorubicin and a daunorubicin standard were separated using an Agilent Zorbax $300 \mathrm{SB} 4.6 \times 150 \mathrm{~mm}, 5-\mu \mathrm{m}$ pore size with a guard column containing the same material (Agilent Technologies, Santa Clara, CA) under isocratic conditions with a mobile phase consisting of $0.1 \%$ trimethylamine, adjusted to $\mathrm{pH} 3$ with phosphoric acid, and HPLC-grade acetonitrile in a ratio of 75:25. Daunorubicin (TEVA, UAMS Hospital Pharmacy, Little Rock, AR) served as an internal standard to verify extraction efficiency across samples as described elsewhere (Alvarez-Cedrón et al., 1999; Wei et al., 2008; Daeihamed et al., 2015). A DOX calibration curve between 5 and $5000 \mathrm{ng} / 1$ $(0.009-9.2 \mu \mathrm{mol} / \mathrm{l})$ showed excellent linearity with a correlation coefficient of 0.9927 .

Intracellular Free Calcium. Rat mesenteric lymph vessels were isolated, cannulated, and equilibrated as described above. Subsequently, vessels were incubated in the dark with $2 \mu \mathrm{mol} / \mathrm{l}$ Fura-2 AM (F1221; ThermoFisher Scientific Molecular Probes, Waltham, MA) and $0.02 \% \mathrm{wt} / \mathrm{v}$ pluronic acid (P2443; Sigma-Aldrich, St. Louis, MO) for 45 minutes at $37^{\circ} \mathrm{C}$, superfused with reagent-free PSS, and equilibrated for 20 minutes until rhythmic contractions were stable. An inverted Eclipse Ti-E microscope (Nikon Instruments Corporation, Melville, NY) equipped with an iXon EMCCD camera (Andor model iXonEM + DU-897; Oxford Instruments, Abingdon, Oxfordshire, England) was used to image lymph vessels loaded with Fura-2 AM. The dye was excited in 50-millisecond exposures at alternating 340and 380-nm wavelengths using a Lambda DG-4 light source (Sutter Instruments, Novato, CA). Fluorescence emission was acquired using a $20 \times$ S Fluor objective at 15 frames per second. Cytosolic free-Ca ${ }^{2+}$ concentration $\left(\left[\mathrm{Ca}_{\mathrm{i}}^{2+}\right]\right.$ ) was calculated as the ratio of $340-/ 380-\mathrm{nm}$ wavelengths calibrated to $\mathrm{Ca}^{2+}$ standards (C3008MP; ThermoFisher Scientific) (Kong and Lee, 1995; Souza-Smith et al., 2011). Data were analyzed using NIS Elements AR software (Nikon Instruments Corporation) after subtraction of background fluorescence. Fluorescence measurements were collected in response to DOX $(10 \mu \mathrm{mol} / \mathrm{l})$, ryanodine (10 and $100 \mu \mathrm{mol} / \mathrm{l})$, nifedipine (NIF; $1 \mu \mathrm{mol} / \mathrm{l}, \mathrm{N} 7634$; Sigma-Aldrich), and 2-aminoethoxydipehnyl borate (2-APB; $100 \mu \mathrm{mol} / \mathrm{l}$, D9754; Sigma-Aldrich).

Chemicals. Doxorubicin $\mathrm{HCl}$ injectable USP and daunorubicin $\mathrm{HCl}$ injectable USP were stored at $4^{\circ} \mathrm{C}$ protected from light. Ryanodine was dissolved in water and stored as $1-\mathrm{mmol} / \mathrm{l}$ aliquots at $-20^{\circ} \mathrm{C}$. Fura-2 AM was dissolved in dimethyl sulfoxide (DMSO) and stored as $1-\mathrm{mmol} / \mathrm{l}$ aliquots at $-20^{\circ} \mathrm{C}$ protected from light. Pluronic $\mathrm{F}-127$ was dissolved in DMSO and stored as $20 \%(\mathrm{wt} / \mathrm{v})$ aliquots at room temperature. Nifedipine and 2-APB were dissolved in DMSO and stored as $1-\mathrm{mmol} / \mathrm{l}$ aliquots at $-20^{\circ} \mathrm{C}$ protected from light.

Statistics. All data were normally distributed as confirmed using the D'Agostino-Pearson normality test. Data obtained from control and DOX- or drug-treated preparations at single time points were compared using the paired $t$ test for statistical significance. Comparison between multiple groups with multiple time points was subjected to two-way ANOVA with repeated measures, and differences between individual means were determined by a Holm-Sidak post-test. Data are expressed as mean \pm S.E.M. Differences were judged to be significant at the level of $P<0.05$.

\section{Results}

DOX Inhibits Rhythmic Contractions of Isolated Lymph Vessels. Under basal conditions, isolated lymph vessels maintained spontaneous rhythmic contractions during recordings designed to study the effect of DOX on contractile parameters (Fig. 1A). End-diastolic diameter (EDD) and contraction amplitude were nearly identical at the start and finish of control recordings in drug-free PSS (Fig. 2, A and B), whereas the parameters of contraction frequency and (as a result) flow, declined by the final measurement of continuous recordings (Fig. 2, C and D). Therefore, data from lymph vessels exposed to DOX and control vessels exposed to PSS were compared at the same time point for statistical analysis. In parallel studies using a 0.5 - to $20-\mu \mathrm{mol} / \mathrm{l}$ concentration range of DOX, we observed that DOX progressively and profoundly disrupted the rhythmic contractions of isolated lymph vessels (Fig. 1, B and C). Washout of DOX in a subset of 8 of the 12 vessels studied restored rhythmic contractions (Fig. 1C), suggesting a reversible pharmacological action of DOX rather than irreversible cell death related to its known cytotoxicity. Collectively, all contractile parameters of the lymph vessels were significantly impacted by DOX compared with control vessels maintained in PSS. DOX maximally reduced EDD to $75.8 \% \pm 5.3 \%$ of initial baseline (Fig. 2A; Table 1) and maximally reduced contraction amplitude to $27.9 \% \pm 8.4 \%$ of initial control amplitude, respectively (Fig. 2B; Table 1). DOX also inhibited contraction frequency (Fig. 2C; Table 1), but this effect was more variable, resulting in either lower frequency of contraction or full inhibition of contraction at the same concentration of DOX, as can be seen by comparing the diameter response to $10 \mu \mathrm{mol} / /$ DOX between Fig. 1, B and C. Estimated flow markedly decreased to $24.2 \% \pm 7.7 \%$ of resting value in response to the highest DOX concentration (Fig. 2D; Table 1).

Superfusion of DOX Inhibits Lymph Flow In Vivo. The use of high-speed optical flow cytometry allows volumetric lymph flow to be calculated by simultaneously tracking individual cell velocities in lymph fluid and vessel diameter (Fig. 3A) (Sarimollaoglu et al., 2018). Under normal conditions, lymph cell velocity is overwhelmingly distal-to-proximal (Fig. 3A; Supplemental Video 1 in Figures \& Data tab), which is registered as an upward deflection in a sample recording of cell velocity (Fig. 3B), and implies efficient pumping of lymph fluid by the contractile machinery of the lymph muscle cells. In contrast, when we superfused DOX (10 $\mu \mathrm{mol} / \mathrm{l})$ across the intestinal loop to expose mesenteric lymph vessels to a defined concentration of the drug, positive cell velocity was markedly reduced (Fig. 3, C and D; Supplemental Video 2), indicating attenuated lymph flow and impaired lymphatic drainage. 
Collectively, superfusion of progressive concentrations of DOX $(0.05-10 \mu \mathrm{mol} / \mathrm{l})$ induced a concentration-dependent loss of positive volumetric lymph flow in vivo (Fig. $3 \mathrm{E}$; Table 2 ). The highest concentration of DOX $(10 \mu \mathrm{mol} / \mathrm{l})$ reduced lymph flow to $34.5 \% \pm 11.6 \%$ of initial values. DOX exhibited a halfmaximal inhibitory concentration $\left(\mathrm{IC}_{50}\right)$ of $1.54 \mu \mathrm{mol} / \mathrm{l}$, which is a drug concentration well within clinically achievable plasma concentrations (Fig. 3E, gray shading). Superfusion of drug-free PSS for a similar period of time did not significantly alter lymph flow (Fig. 3E).

Clinical Plasma Concentrations of DOX Attenuate Lymph Flow In Vivo. Detailed studies comparing DOX pharmacokinetics in rodents, dogs, and humans, and also predictive models of DOX pharmacokinetics, have been published (Rahman et al., 1986; Alvarez-Cedrón et al., 1999; Gustafson et al., 2002; Wei et al., 2008; Daeihamed et al., 2015). However, we sought to administer DOX by intravenous infusion to establish a clinically achievable plasma concentration of DOX and confirm that systemic administration of DOX results in reduced lymph flow. A separate pharmacokinetic study using DOX (10 mg/kg i.v.) was conducted in five rats. We used HPLC to detect DOX in plasma, using daunorubicin (DAUN) as an internal standard (Fig. 4A). We also confirmed that clinical plasma concentrations were achieved in our animals and determined the optimal time to image lymph vessels during the slow plateau phase of elimination associated with tissue release of DOX. Doxorubicin displayed a pharmacokinetic profile in rats similar to that seen in patients after rapid intravenous infusion. The initial distributive half-life of DOX is characterized by rapid tissue uptake, after which DOX is slowly eliminated from tissues by active transport with a terminal half-life of 20-48 hours in rats (Alvarez-Cedrón et al., 1999; Wei et al., 2008; Daeihamed et al., 2015). In our rat model, the plateau phase of DOX elimination correlating to tissue release and therapeutic plasma concentrations occurred between 45 and 240 minutes after rapid infusion of DOX (10 mg/kg) via tail vein (Fig. 4B). The average plasma concentrations of DOX were $0.23 \pm 0.04$ and $0.10 \pm 0.02 \mu \mathrm{mol} / \mathrm{l}$ at 30 and 120 minutes after infusion, respectively $(n=5)$. These values are in the lower range of the DOX concentrations used by us to superfuse intact lymph vessels in vivo (Fig. 3) and within the clinically achievable plasma concentration range for DOX of $\leq 5 \mu \mathrm{mol} / \mathrm{l}$ (Fig. $4 \mathrm{~B}$, gray shading) (de Bruijn et al., 1999; Perez-Blanco et al., 2014). On the basis of these pharmacokinetic results, we measured mesenteric lymph flow continuously for 15 minutes before and then continuously for 100 minutes after infusion of DOX, or after infusion of an equal volume of drug-free isotonic saline (SAL) as a time control.

In saline-infused animals, positive volumetric lymph flow tended to increase above baseline, probably reflecting volume expansion after infusion of $1 \mathrm{ml}$ of SAL, which represents approx. 10\% of rat blood volume (Diehl et al., 2001) and is within the dose volume guideline of $5 \mathrm{ml} / \mathrm{kg}$ body weight (Turner et al., 2011). Therefore, data from DOX-infused animals and SAL-infused animals $(n=6)$ were compared at the same time point for statistical analysis. Compared with stable values for positive volumetric lymph flow in salineinfused animals (Fig. 4C; Supplemental Video 3 in Figures \& Data tab), a rapid intravenous infusion of DOX $(10 \mathrm{mg} / \mathrm{kg})$ significantly reduced positive volumetric flow to $60.9 \% \pm 11.9 \%$ of baseline by 40 minutes, and flow remained depressed for an
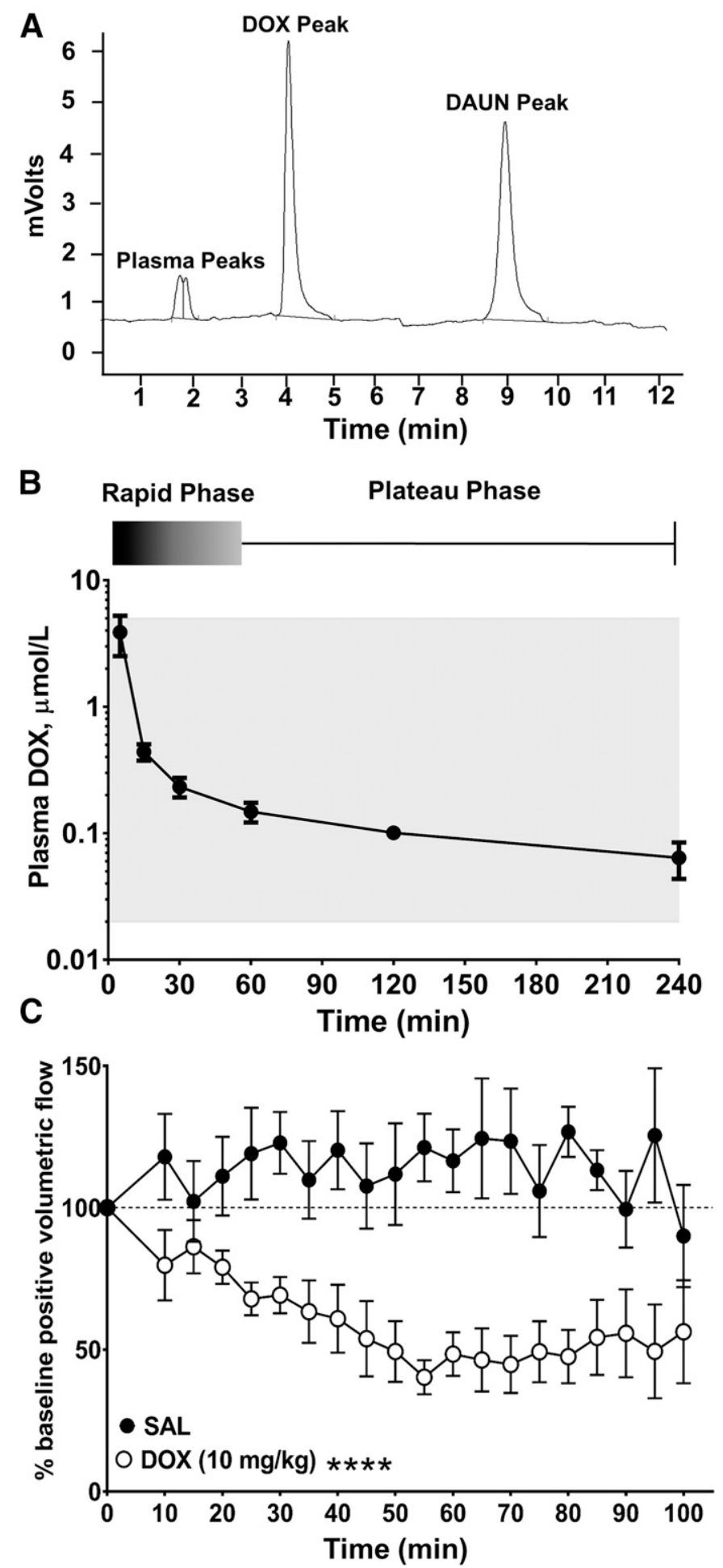

Fig. 4. Intravenous push infusion of DOX disrupts lymph flow in rat mesenteric lymph vessels in vivo. (A) HPLC chromatogram reveals a retention time of 4.36 minutes for DOX. Daunorubicin (DAUN) was used as an internal standard and eluted at 9.21 minutes. (B) DOX $(10 \mathrm{mg} / \mathrm{kg}$ ) was administered via rapid tail-vein infusion and blood collected and analyzed by HPLC as described in Materials and Methods. An initial rapid elimination phase of approx. 45 minutes was followed by a plateau phase corresponding to tissue release. Gray shading denotes clinically achievable plasma concentrations of DOX at $\leq 4$ hours after an intravenous push infusion. Data reported as mean \pm S.E.M. $(n=5)$. (C) Compared with saline, systemic administration of DOX significantly and persistently decreased positive volumetric flow in rat mesenteric lymph vessels $[\mathrm{F}(1,14)=35.53]$. Data reported as mean \pm S.E.M. and analyzed using two-way ANOVA with Holm-Sidak post-test $(n=8$; **** $P<0.0001)$. 
additional hour until the end of the recording period (Fig. 4C; Supplemental Video 4) in Figures \& Data tab). For example, at 70 and 85 minutes after DOX infusion, positive volumetric lymph flow averaged $44.8 \% \pm 10.1 \%$ and $54.3 \% \pm 13.2 \%$ of baseline, respectively (Tables 3 ). Thus, clinically achievable plasma concentrations of DOX appear to directly impair lymph flow in vivo, revealing a newly discovered action of DOX on lymphatic function.

DOX Activates RYRs to Disrupt $\mathrm{Ca}^{2+}$ Signaling and Contraction. Finally, we sought to determine the potential mechanism by which DOX inhibits the rhythmic contractions of collecting lymph vessels and reduces lymph flow. The basis of our initial studies was earlier reports indicating that DOX activates RYRs and interferes with $\mathrm{Ca}^{2+}$ signaling in striated muscle cells (Abramson et al., 1988; Keung et al., 1991; Kim et al., 2006; Hanna et al., 2014). The RYRs are intracellular calcium-release channels in the sarcoplasmic reticulum that contribute to the concentration of cytosolic free calcium $\left(\left[\mathrm{Ca}_{\mathrm{i}}^{2+}\right]\right.$ ) in striated and smooth muscle cells (Fill and Copello, 2002). In contrast, the effect of DOX on RYRs and $\mathrm{Ca}^{2+}$ signaling in lymphatic muscle cells has yet to be established. Indeed, under basal conditions, the RYRs are not regarded as contributing significantly to rhythmic contractions in isolated lymph vessels (Atchison et al., 1998; Zhao and van Helden, 2003), and the molecular identity of the functional RYRs in lymphatic muscle cells is unknown (Muthuchamy et al., 2003), although isoforms RYR2 and RYR3 recently were detected in the smooth muscle layer of rat mesenteric collecting lymph vessels (Jo et al., 2019). Regardless, we considered whether the pharmacological activation of otherwise quiescent RYRs by DOX may explain its disruption of lymphatic rhythmic contractions. Initial studies were designed only to confirm the expression of functional RYRs in isolated lymph vessels. In these experiments, isolated lymph vessels were loaded with Fura-2 AM and monitored for calcium fluorescence. As did earlier researchers (Souza-Smith et al., 2011), we observed rhythmic $\mathrm{Ca}^{2+}$ spikes of 200- to 300-nM amplitudes under resting conditions (Supplemental Fig. 1A). Addition of the universal RYR agonist ryanodine (Ryan, $10 \mu \mathrm{mol} / \mathrm{l}$ ) caused a steady-state elevation of resting $\left[\mathrm{Ca}_{\mathrm{i}}^{2+}\right]$, thereby verifying that $R Y R$ activation can influence $\mathrm{Ca}^{2+}$ signaling in lymphatic muscle cells (Supplemental Fig. 1A). Collectively in five lymph vessels, ryanodine $(10 \mu \mathrm{mol} / \mathrm{l})$ caused a persistent elevation of resting $\left[\mathrm{Ca}_{\mathrm{i}}^{2+}\right]$ to $133.8 \% \pm 12.1 \%$ of baseline, indicative of $\mathrm{Ca}^{2+}$ leak from the sarcoplasmic reticulum (Supplemental Fig. 1B).

Subsequent studies explored the effect of DOX on $\mathrm{Ca}^{2+}$ signaling in isolated lymph vessels loaded with Fura-2 AM. Dual measurements of calcium fluorescence and contraction were recorded for this analysis. Lymph vessels used as time and solvent controls showed a continuous pattern of intracellular $\mathrm{Ca}^{2+}$ spikes (Fig. 5A, in blue), which corresponded to rhythmic contractions (Fig. 5A, in black). In these studies, the addition of aliquots of solvent or drug to the bath briefly disturbed $\mathrm{Ca}^{2+}$ spikes and rhythmic contractions, so measurements used for statistical comparison were averaged for 5 minutes after recordings had returned to stability. In similar lymph vessels, a DOX concentration $(10 \mu \mathrm{mol} / \mathrm{l})$ used to acutely activate RYRs and increase $\left[\mathrm{Ca}_{\mathrm{i}}^{2+}\right]$ in other cell types (Abramson et al., 1988; Pessah et al., 1990; Shen et al., 2009) caused a steady-state elevation of resting $\left[\mathrm{Ca}_{\mathrm{i}}^{2+}\right]$ consistent with $\mathrm{Ca}^{2+}$ leak from RYRs (Fig. 5B, in blue), which was associated with a reduction in vessel diameter and inhibition of rhythmic contractions (Fig. 5B, in black). Collectively, in seven lymph vessels, DOX increased resting $\left[\mathrm{Ca}_{\mathrm{i}}^{2+}\right]$ by $123.1 \% \pm 11.5 \%$ and this change was associated with a reduction in end-diastolic diameter and contraction amplitude to $93.9 \% \pm 2.7 \%$ and $75.9 \% \pm 7.9 \%$ of baseline, resulting in a marked reduction in flow to $75.2 \% \pm$ $8.9 \%$ of initial values (Fig. 6 , open bars, Table 4 ). The smaller inhibitory effect of DOX on contractions in $\mathrm{Ca}^{2+}$ imaging studies using lymph vessels loaded with Fura-2 AM (Fig. 5B, in black) compared with our initial studies in lymph vessels not subjected to fluorescence imaging (Fig. 1, B and C) may relate to chelation of free intracellular $\mathrm{Ca}^{2+}$ by Fura-2 AM as the mechanism of calcium fluorescence, resulting in dampening of $\mathrm{Ca}^{2+}$ transients.

Importantly, DOX-induced disruption of normal $\mathrm{Ca}^{2+}$ signaling in isolated lymph vessels was prevented by pharmacological block of RYRs, which was achieved using a $100 \mu \mathrm{mol} / \mathrm{l}$ concentration of ryanodine (Fig 6, Table 4). Ryanodine has a dual pharmacological effect on RYRs; lower concentrations $(\leq 10 \mu \mathrm{mol} / \mathrm{l})$ activate $\mathrm{RYRs}$, whereas high concentrations ( $>100 \mu \mathrm{mol} / \mathrm{l}$ ) lock RYRs in the closed state (Fill and Copello, 2002). RYR block per se had little effect on $\left[\mathrm{Ca}_{\mathrm{i}}^{2+}\right]$ or lymph vessel contractions (Supplemental Fig. 1, C and D), which is a finding consistent with earlier reports describing a minimal influence of RYRs on rhythmic contractions (Atchison et al., 1998; Zhao and van Helden, 2003). We observed only an initial increase in resting $\left[\mathrm{Ca}_{\mathrm{i}}^{2+}\right]$ after addition of $100 \mu \mathrm{mol} / \mathrm{l}$ ryanodine, which we attributed to a transient activation of RYRs prior to establishment of block. Lymph vessels incubated in a blocking concentration of $100 \mu \mathrm{mol} / \mathrm{l}$ ryanodine failed to elevate resting $\left[\mathrm{Ca}_{\mathrm{i}}^{2+}\right]$ in response to $10 \mu \mathrm{mol} / \mathrm{LOX}$ (Fig. 5C, in blue; Fig. 6, gray bars, Table 4). In the same lymph vessels, DOX transiently reduced the amplitude of rhythmic contractions after pharmacological block of RYRs, but basal contractile parameters were stably restored by 15-20 minutes after addition of DOX (Fig. 5C, in black; Fig. 6, gray bars, Table 4). Although the identity of the functional RYR isoforms expressed by rat mesenteric lymphatic muscle cells is unclear, we also briefly explored whether the clinically available medication dantrolene, which is marketed as an antagonist of RYR 1 for the treatment of malignant hyperthermia and muscle spasticity (Krause et al., 2004), was able to prevent DOX-induced disruption of rhythmic contractions. Indeed, dantrolene $(10 \mu \mathrm{mol} / \mathrm{l})$ preserved lymphatic contractile function in isolated rat mesenteric lymph vessels exposed to DOX (Supplemental Fig. 2), implying a contribution by RYR1 to DOX-induced disruption of calcium signaling in lymphatic muscle cells.

We also considered that DOX administration appeared to cause more erratic rhythmic contractions in isolated lymph vessels than RYR activation alone, implying that DOX may exert discrete effects on proteins other than RYRs involved in intracellular $\mathrm{Ca}^{2+}$ signaling and contractile protein activation, as has been reported for striated muscle cells (Abramson et al., 1988; Keung et al., 1991; Kim et al., 2006; Hanna et al., 2014). Thus, we investigated whether other $\mathrm{Ca}^{2+}$-conducting channels important to the normal rhythmic contractions of lymph vessels, namely the $\mathrm{IP}_{3}$ receptors and $\mathrm{Ca}_{\mathrm{v}} 1.2$ channels, also may be at least transiently activated by DOX. However, incubation of isolated lymph vessels with the $\mathrm{Ca}_{\mathrm{v}} 1.2$ channel blocker nifedipine $(1 \mu \mathrm{mol} / \mathrm{l})$ halted rhythmic contractions, but failed to prevent the subsequent $\left[\mathrm{Ca}_{\mathrm{i}}^{2+}\right]$ elevation induced by 
TABLE 3

An intravenous push infusion of DOX disrupts lymph flow in rat mesenteric lymph vessels in vivo

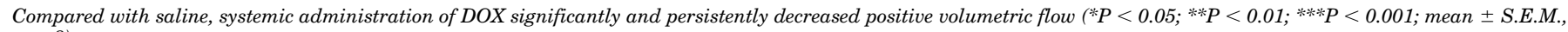
$n=8)$.

\begin{tabular}{|c|c|c|}
\hline Time (min) & intravenous SAL & intravenous DOX $10 \mathrm{mg} / \mathrm{kg}$ \\
\hline 10 & $117.9 \pm 15.1$ & $79.8 \pm 12.4$ \\
\hline 15 & $102.2 \pm 14.2$ & $86.3 \pm 9.4$ \\
\hline 20 & $111.1 \pm 13.8$ & $79.0 \pm 5.9$ \\
\hline 25 & $119.1 \pm 16.2$ & $67.9 \pm 5.8^{*}$ \\
\hline 30 & $122.9 \pm 10.9$ & $69.2 \pm 6.4^{*}$ \\
\hline 35 & $109.8 \pm 13.7$ & $63.4 \pm 11.0$ \\
\hline 40 & $120.3 \pm 13.7$ & $60.9 \pm 11.9^{*}$ \\
\hline 45 & $107.7 \pm 15.0$ & $53.8 \pm 13.3^{*}$ \\
\hline 50 & $111.8 \pm 17.9$ & $49.3 \pm 10.7^{*}$ \\
\hline 55 & $121.2 \pm 11.9$ & $40.3 \pm 6.0 * * *$ \\
\hline 60 & $116.6 \pm 11.1$ & $48.4 \pm 7.7 * *$ \\
\hline 65 & $124.4 \pm 21.2$ & $46.4 \pm 11.1 * * *$ \\
\hline 70 & $123.4 \pm 18.6$ & $44.8 \pm 10.1^{* * *}$ \\
\hline 75 & $105.9 \pm 16.2$ & $49.3 \pm 10.8^{*}$ \\
\hline 80 & $126.7 \pm 8.9$ & $47.6 \pm 9.4^{* * *}$ \\
\hline 85 & $113.3 \pm 7.0$ & $54.3 \pm 13.2^{*}$ \\
\hline 90 & $99.5 \pm 13.5$ & $55.8 \pm 15.5$ \\
\hline 95 & $125.5 \pm 23.6$ & $49.4 \pm 16.5^{* * *}$ \\
\hline 100 & $90.1 \pm 18.0$ & $56.3 \pm 18.2$ \\
\hline
\end{tabular}

$10 \mu \mathrm{mol} / / \mathrm{DOX}$ (Supplemental Fig. 3A). Likewise, pharmacological block of $\mathrm{IP}_{3}$ receptors by 2 -APB $(100 \mu \mathrm{mol} / \mathrm{l})$ halted rhythmic contractions, but did not preclude elevation of $\left[\mathrm{Ca}_{\mathrm{i}}^{2+}\right]$ by $10 \mu \mathrm{mol} / \mathrm{l}$ of DOX (Supplemental Fig. 3B). Instead, in the presence of nifedipine and 2-APB, DOX increased $\left[\mathrm{Ca}_{\mathrm{i}}^{2+}\right]$ by $161.2 \% \pm 19.3 \%$ and $155.4 \% \pm 10.6 \%$ above baseline values,
A

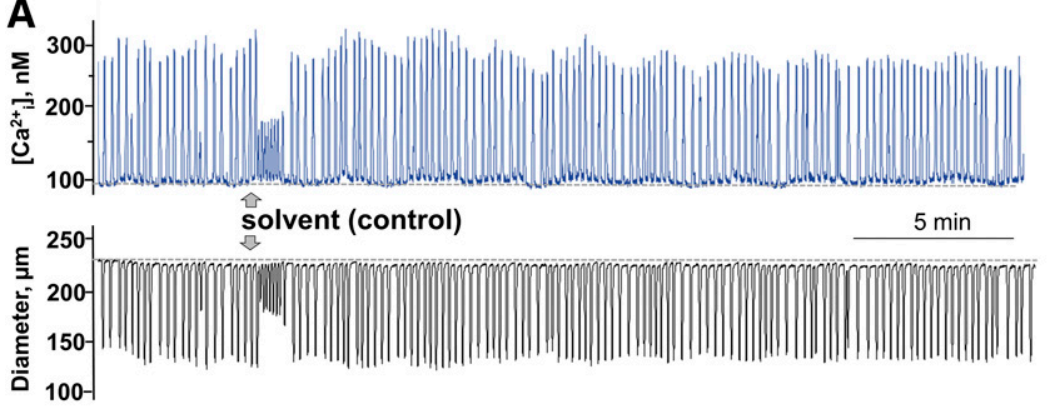

B

\section{(a)}

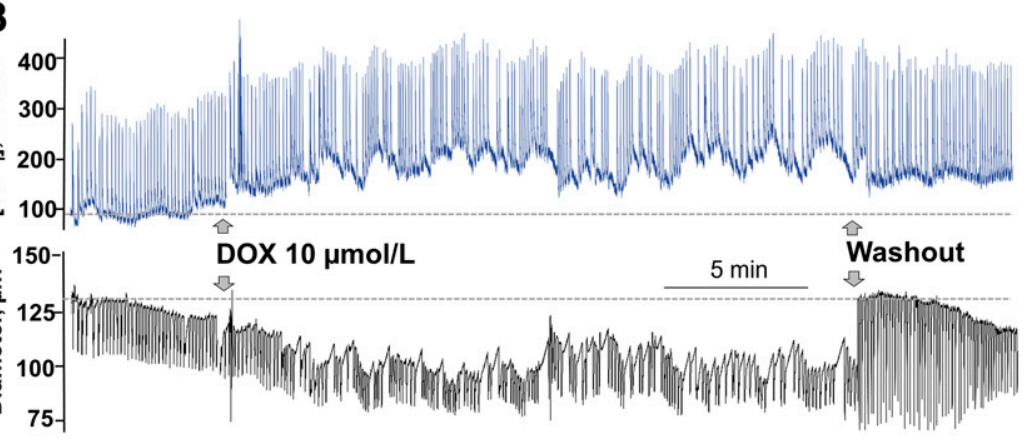

C

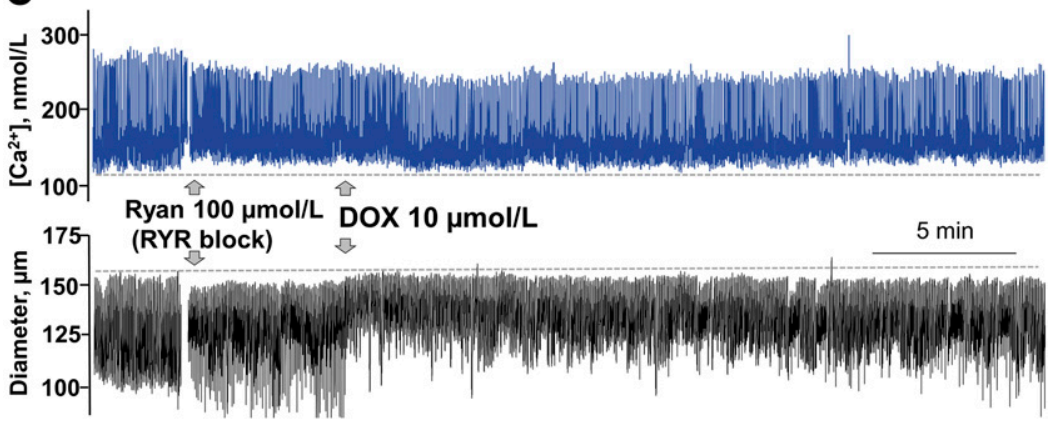

Fig. 5. DOX fails to increase resting $\left[\mathrm{Ca}_{i}^{2+}\right]$ or inhibit rhythmic contractions in isolated lymph vessels after pharmacological block of RYRs. (A) Temporally matched control recordings in PSS of $\left[\mathrm{Ca}_{\mathrm{i}}^{2+}\right]$ (in blue) and diameter (in black) in an individual lymph vessel; drug-free PSS was added to the bath as indicated by arrows. (B) Recordings of $\left[\mathrm{Ca}_{\mathrm{i}}^{2+}\right]$ (in blue) and diameter (in black) in another lymph vessel. DOX $(10 \mu \mathrm{mol} / \mathrm{l})$ was added to the bath and later washed out with PSS as indicated by arrows. (C) Recordings of $\left[\mathrm{Ca}_{\mathrm{i}}^{2+}\right.$ (in blue) and diameter (in black) in another lymph vessel. After addition of a high concentration of ryanodine (Ryan, $100 \mu \mathrm{mol} / \mathrm{l}$ ) to block RYRs, DOX (10 $\mu \mathrm{mol} / \mathrm{l})$ failed to elevate resting $\left[\mathrm{Ca}_{\mathrm{i}}^{2+}\right]$ and only transiently attenuated rhythmic contractions. The broken line in each recording represents baseline. 


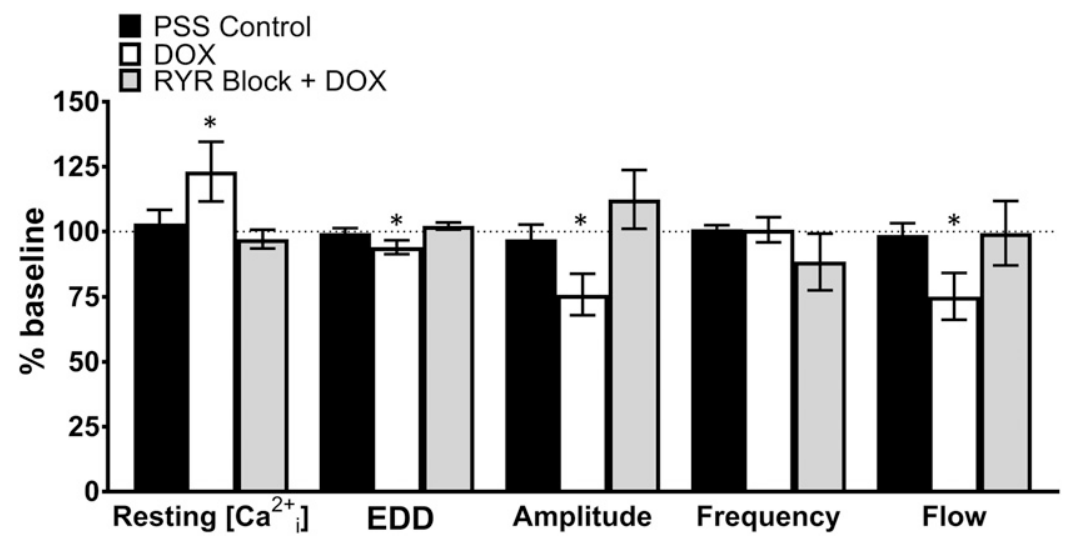

Fig. 6. Effect of DOX and RYR block on $\left[\mathrm{Ca}_{\mathrm{i}}^{2+}\right]$, rhythmic contractions, and flow in isolated lymph vessels. Compared with baseline values, DOX $(10 \mu \mathrm{mol} / \mathrm{l})$ increased resting $\left[\mathrm{Ca}_{\mathrm{i}}^{2+}\right]$, reduced end-diastolic diameter, and decreased contraction amplitude, resulting in attenuation of flow. Block of RYRs by a high concentration of ryanodine $(100 \mu \mathrm{mol} / \mathrm{l})$ prevented the effects of DOX. Data reported as mean \pm S.E.M. and analyzed using paired $t$ test $(n=5-7 ; * P<0.05)$.

respectively ( $n=5,4)$. These values were not statistically different from the $123.1 \% \pm 11.5 \%$ elevation of $\left[\mathrm{Ca}_{\mathrm{i}}^{2+}\right]$ caused by DOX in blocker-free PSS devoid of pharmacological antagonists (Fig. 5B; Fig. 6).

\section{Discussion}

Our findings demonstrate for the first time to our knowledge that DOX acts directly on RYRs to inhibit the contractile activity of collecting lymph vessels and impair lymph flow. Although DOX chemotherapy greatly increases the incidence and severity of secondary lymphedema in cancer patients exposed to surgery and/or radiation (Norman et al., 2010; Ahmed et al., 2011; Bevilacqua et al., 2012), the mechanism of this off-target effect has not been explored in depth and has been largely attributed to its cytotoxic properties. The present study provides initial evidence for a direct pharmacological action of DOX on the lymphatic circulation at clinically achievable plasma concentrations, which is reversible and appears distinct from its known cytotoxic action. In vivo, intravenous infusion of DOX to achieve therapeutic plasma concentrations markedly reduces lymph flow, an adverse event linked to an acute rise in intravascular pressure, and causes acute injury to the lymph vessel endothelium, muscle cells, and valves, culminating in secondary lymphedema (Ji and Kato, 2001). Moreover, our findings argue that DOX serves as an agonist of RYRs in lymphatic muscle cells, inducing "calcium leak" and disrupting the cyclic changes in $\left[\mathrm{Ca}_{\mathrm{i}}^{2+}\right]$ that underlie the rhythmic contractions of lymph vessels. In isolated lymph vessels, the disruption of $\mathrm{Ca}^{2+}$ signaling was observed to compromise rhythmic contractions and markedly attenuate distal-to-proximal flow. These detrimental effects of DOX on isolated lymph vessels were prevented by pharmacological block of RYRs, identifying the RYR family of proteins as potential therapeutic targets for future antilymphedema medications.

We used the rat mesenteric lymphatic circulation as our model system, because it provides multiple lymph vessels from a single animal for isolated vessel studies. Additionally, it consists of a transparent sheet of connective tissue enclosing a single layer of collecting lymph vessels, which can be subjected to high-speed optical imaging to estimate lymph flow in vivo (Galanzha et al., 2007a,b, 2008; Fedosov et al., 2016; Sarimollaoglu et al., 2018). Using this preparation, we initially evaluated the direct effect of DOX on rhythmic contractions, a unique feature of lymphatic collecting vessels that enables the distal-to-proximal "pumping" of lymph fluid to limit rises in interstitial pressure (Gashev, 2002). We measured the end-diastolic diameter, contraction frequency, and contraction amplitude of isolated lymph vessels; these three parameters positively correlate to lymph flow (Scallan et al., 2016). Notably, since DOX concentrations in lymph fluid are unknown, we used clinically achievable plasma concentrations $(\leq 5 \mu \mathrm{mol} / \mathrm{l})$ as a surrogate to define the DOX concentrations used in our studies (de Bruijn et al., 1999; Perez-Blanco et al., 2014). These concentrations concur with those reported for in vitro drug studies evaluating the effects of DOX on $\mathrm{Ca}^{2+}$ signaling in striated and smooth muscle cells (Kim et al., 2006; Shen et al., 2009). Importantly, DOX inhibited rhythmic contractions and reduced flow within the range of clinically achievable plasma concentrations associated with chemotherapy (Kim et al., 2006; Shen et al., 2009).

To our knowledge, our study is the first to apply high-speed optical flow cytometry to explore the effect of DOX on lymph flow in vivo. Lymph flow in its native setting is characterized by unstable, turbulent, and oscillating motion with temporal

TABLE 4

Effect of DOX and RYR block on $\left[\mathrm{Ca}_{\mathrm{i}}^{2+}\right]$, rhythmic contractions, and calculated flow in isolated lymph vessels

Compared with baseline values, DOX $\left(10 \mu\right.$ mol/l) increased resting $\left[\mathrm{Ca}_{i}^{2+}\right]$, reduced end-diastolic diameter, and decreased contraction

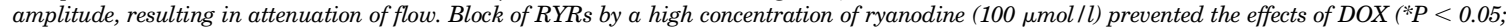
mean \pm S.E.M., $n=4-7)$.

\begin{tabular}{lrrr}
\hline & \multicolumn{1}{c}{ PSS } & DOX & RYR Block + DOX \\
\hline Resting $\left[\mathrm{Ca}_{\mathrm{i}}^{2+}\right]$ & $103.1 \pm 5.3$ & $123.1 \pm 11.5^{*}$ & $96.5 \pm 4.6$ \\
EDD & $99.4 \pm 1.9$ & $93.9 \pm 2.7^{*}$ & $102.9 \pm 1.5$ \\
Amplitude & $97.1 \pm 5.6$ & $75.9 \pm 7.9^{*}$ & $116.4 \pm 13.7$ \\
Frequency & $100.9 \pm 1.5$ & $100.7 \pm 4.8$ & $88.4 \pm 13.9$ \\
Flow & $98.7 \pm 4.6$ & $75.2 \pm 8.9^{*}$ & $102.9 \pm 15.3$ \\
\hline
\end{tabular}


and spatial cell fluctuations (Schmid-Schönbein, 1990; Galanzha et al., 2007a). Thus, unlike isolated lymph vessels in which changes in lymph flow can be estimated by monitoring vessel diameter, the rhythmic contractions that establish lymph flow in the intact lymphatic circulation may be upstream from the imaged vessel segment under study. As a result, diameter measurements per se cannot be used to predict lymph flow in vivo. Importantly, high-speed optical flow cytometry mitigates these confounders by estimating flow on the basis of the movement of cells in lymph fluid as a function of time.

We leveraged this method to explore the effect of DOX on the intact rat mesenteric lymphatic circulation. In an initial set of studies, DOX was added to the physiologic solution directly bathing the mesentery to tightly control the concentration of DOX. In these studies, DOX markedly reduced lymph flow in vivo at clinically achievable plasma concentrations. Next, we administered DOX by intravenous infusion to recapitulate the clinical situation in which drug distribution, pharmacokinetics, and metabolism influence drug availability. We modeled our protocol for systemic administration of DOX after a common breast cancer treatment regimen in which DOX $\left(60 \mathrm{mg} / \mathrm{m}^{2}\right)$ is administered as an intravenous push infusion over 5-15 minutes, resulting in peak plasma concentrations between 2.5 and $5 \mu \mathrm{mol} / 1$, which decline to $\leq 0.1 \mu \mathrm{mol} / \mathrm{l}$ by $1-4$ hours after infusion (de Bruijn et al., 1999; Perez-Blanco et al., 2014). We used pharmaceutical industry guidelines that convert animal doses into clinical doses, to reverse calculate from a clinically relevant dose of DOX $\left(60 \mathrm{mg} / \mathrm{m}^{2}\right.$ i.v. $)$ to the dose (10 mg/kg i.v.) we administered to rats (FDA Center for Drug Evaluation and Research, 2005). Using this strategy, HPLC findings confirmed that we achieved clinical plasma concentrations of DOX in our animals. Our pharmacokinetic studies also defined the slow plateau phase of DOX elimination that corresponds to tissue release of DOX, which we regarded as the optimal window for assessing DOX-induced changes in lymph flow. Ultimately, we observed that systemic administration of DOX markedly and persistently reduced lymph flow in vivo at clinically achievable plasma concentrations.

Our finding that DOX opens RYRs to elevate $\left[\mathrm{Ca}_{\mathrm{i}}^{2+}\right]$ persistently in lymphatic muscle cells was unexpected, considering that the contribution of RYR-mediated $\mathrm{Ca}^{2+}$ release to rhythmic contractions in lymph vessels is regarded as minimal under basal conditions. The basis of this conclusion is the observation that pharmacological RYR blockers fail to alter lymphatic rhythmic contractions (Atchison et al., 1998; Zhao and van Helden, 2003), an observation confirmed in the present study. In contrast, it is known that RYRs in cardiac and skeletal myocytes contribute in a major way to the spike in $\left[\mathrm{Ca}_{\mathrm{i}}^{2+}\right]$ necessary for contraction. Three isoforms (RYR1, RYR2, RYR3) of the RYRs have been identified and they are expressed in a tissue-specific pattern (Fill and Copello, 2002). The RYR1 and RYR2 isoforms are preferentially expressed by skeletal muscle cells and cardiac myocytes, respectively, and DOX reportedly activates both of these RYR isoforms (Abramson et al., 1988; Kim et al., 2006). In contrast, the RYR isoform(s) expressed by lymphatic muscle cells are not well defined and not easily predicted, since lymphatic muscle cells are unique "hybrid" cells that express genes and show properties of smooth and striated muscle (Muthuchamy et al., 2003). For example, the $\mathrm{Ca}^{2+}$-dependent rhythmic contractions of lymph vessels are reminiscent of cardiac cells. However, both cardiac and some smooth muscle cells display spontaneous depolarizations, which trigger voltage-dependent $\mathrm{Ca}^{2+}$ influx through dihydropyridine-sensitive $\mathrm{Ca}_{\mathrm{v}} 1.2$ channels to fuel rhythmic contractions, a feature also shared by lymphatic muscle cells (Atchison and Johnston, 1997; Gashev, 2002; Zawieja, 2009; Lee et al., 2014). Notably, a recent study showed amplification of transcripts encoding all three RYR isoforms from rat mesenteric collecting lymph vessels, and detected RYR2 and RYR3 proteins in the muscle layer of these vessels; studies to detect the RYR1 protein apparently were not performed (Jo et al., 2019). Interestingly, RNAseq data obtained from human dermal lymphatics also detected all three RYR isoform genes (Hasselhof et al., 2016). Future studies will be necessary to precisely define the RYR isoforms expressed in lymphatic muscle cells and identify which pharmacological and physiologic stimuli induce their activation.

Some limitations of our study should be acknowledged. First, these studies were conducted in male rats. Notably, secondary lymphedema occurs distally to surgical intervention and/or radiation of the breast, lower limbs, abdomen, genitals, and other anatomic sites in male and female patients (Cormier et al., 2010; Norman et al., 2010; Ahmed et al., 2011; Bevilacqua et al., 2012; Shah et al., 2012b; Shaitelman et al., 2015; Rivere and Klimberg, 2018), and the risk of developing lymphedema after breast cancer treatment is similar between men and women (Reiner et al., 2011). However, given the much higher incidence of breast cancer in women compared with men (Anderson et al., 2010) and the prominence of arm lymphedema after breast cancer surgery with adjunct chemotherapy, future studies will be important to verify that DOX compromises lymph flow in female animal subjects. Second, the limited duration of our studies does not permit conclusions about the long-term impact of DOX administration on lymphatic function. For example, it is unclear whether the abnormalities of contractile behavior and lymph flow observed in our model would persist in the days or weeks following DOX infusion as a prelude to secondary lymphedema, which is often diagnosed weeks to months after chemotherapy ends in patients (Norman et al., 2010). Third, it is well established that DOX administration is associated with oxidative stress, which has been broadly implicated in DOX-induced cardiotoxicity (Renu et al., 2018; Corremans et al., 2019). Additionally, DOX also has been shown to inhibit $\mathrm{Ca}^{2+}$-ATPase (SERCA) pump activity and influence other $\mathrm{Ca}^{2+}$ signaling pathways in cardiac myocytes (Hanna et al., 2014; Renu et al., 2018). In our study, DOX administration appeared to transiently disrupt rhythmic contractions more than RYR activation alone, implying that DOX may have other molecular targets in addition to RYRs in the lymphatic vasculature that contribute to its ability to tonically elevate $\left[\mathrm{Ca}_{i}^{2+}\right]$ to inhibit rhythmic contractions and attenuate lymph flow. However, we failed to find evidence that the " $\mathrm{Ca}^{2+}$ leak" induced by DOX in lymphatic muscle cells relied on activation of $\mathrm{Ca}_{\mathrm{v}} 1.2$ channels or $\mathrm{IP}_{3}$ receptors.

Interestingly, the ability to disrupt $\mathrm{Ca}^{2+}$ signaling also is a feature of other anthracycline medications (Olson et al., 2000; Shadle et al., 2000; Hanna et al., 2011), for example, daunorubicin, raising the possibility of a potentially classwide effect of anthracyclines on lymphatic contractile function 
that may account for their shared association with the development of secondary lymphedema. Future studies using noninvasive serial imaging of the intact lymphatic circulation may clarify the relationship between the short and long-term effects of DOX and other anthracyclines on lymphatic function and evaluate whether RYR blockers can prevent these medications from disrupting lymph flow. Finally, our studies did not pursue the molecular identity of RYRs expressed by lymphatic muscle cells, which will require a detailed analysis of pure populations of lymphatic myocytes to avoid mistakenly attributing RYR transcript or protein signals arising from endothelium or fibroblasts to muscle cells. Additionally, in the absence of definitive isoform-specific antagonists, gene knockdown studies will be required to evaluate the functional significance of RYR1, RYR2, and RYR3. For these reasons, the present study purposely used a high concentration (100 $\mu \mathrm{mol} / \mathrm{l})$ of ryanodine to pharmacologically silence all RYR isoforms in the lymph vessels. However, if the identity of the RYRs in lymphatic muscle cells includes the RYR1 isoform, the clinically available medication dantrolene, which is marketed as an antagonist of RYR1 for the treatment of malignant hyperthermia and muscle spasticity (Krause et al., 2004), may have utility as a medication to alleviate the secondary lymphedema associated with DOX chemotherapy. In a proof of principle study, we incubated isolated lymph vessels with dantrolene prior to applying increasing concentrations of DOX. Indeed, dantrolene preserved lymphatic contractile function in the presence of DOX (Supplemental Fig. 2).

Collectively, our findings raise the possibility that pharmacological blockers of RYRs coadministered with DOX during chemotherapy sessions may represent the first class of medications to protect against secondary lymphedema in patients exposed to DOX chemotherapy. Additionally, our finding that DOX inhibits lymph flow in vivo may have important consequences for our understanding of the antineoplastic mechanisms of DOX. During malignancies including breast cancer, metastatic cells shed by tumors primarily disseminate from the primary tumor via the lymphatic drainage (Rahman and Mohammed, 2015). Thus, our data raise the possibility that DOX reduces tumor cell dissemination by attenuating lymph drainage from the tumor site as an unrecognized therapeutic action, acknowledging that the pharmacological profile of tumor lymphatics may be distinct from normal collecting lymph vessels. Regardless, studies of the lymphatic circulation have the potential to enable therapeutic targeting of the lymphatic system to alleviate secondary lymphedema and introduce new adjunct medications to mitigate the spread of malignancies.

\section{Authorship Contributions}

Participated in research design: Stolarz, Marecki, Galanzha, Rhee, Klimberg, Zharov, Rusch.

Conducted experiments: Stolarz, Marecki, Fletcher, Galanzha

Contributed new reagents or analytic tools: Sarimollaoglu, Galanzha, Zharov.

Performed data analysis: Stolarz, Sarimollaoglu, Marecki, Rhee.

Wrote or contributed to the writing of the manuscript: Stolarz, Sarimollaoglu, Marecki, Galanzha, Rhee, Zharov, Klimberg, Rusch.

\section{References}

Abramson JJ, Buck E, Salama G, Casida JE, and Pessah IN (1988) Mechanism of anthraquinone-induced calcium release from skeletal muscle sarcoplasmic reticulum. J Biol Chem 263:18750-18758.
Ahmed RL, Schmitz KH, Prizment AE, and Folsom AR (2011) Risk factors for lymphedema in breast cancer survivors, the Iowa Women's Health Study. Breast Cancer Res Treat 130:981-991.

Alvarez-Cedrón L, Sayalero ML, and Lanao JM (1999) High-performance liquid chromatographic validated assay of doxorubicin in rat plasma and tissues. J Chromatogr B Biomed Sci Appl 721:271-278.

Anderson WF, Jatoi I, Tse J, and Rosenberg PS (2010) Male breast cancer: a population-based comparison with female breast cancer. J Clin Oncol 28:232-239.

Atchison DJ and Johnston MG (1997) Role of extra- and intracellular $\mathrm{Ca}^{2+}$ in the lymphatic myogenic response. Am J Physiol 272 (1):R326-R333.48.

Atchison DJ, Rodela H, and Johnston MG (1998) Intracellular calcium stores modulation in lymph vessels depends on wall stretch. Can J Physiol Pharmacol 76 $367-372$.

Bevilacqua JLB, Kattan MW, Changhong Y, Koifman S, Mattos IE, Koifman RJ, and Bergmann A (2012) Nomograms for predicting the risk of arm lymphedema after axillary dissection in breast cancer. Ann Surg Oncol 19:2580-2589.

Choi I, Lee S, and Hong YK (2012) The new era of the lymphatic system: no longer secondary to the blood vascular system. Cold Spring Harb Perspect Med 2:a006445. Cormier JN, Askew RL, Mungovan KS, Xing Y, Ross MI, and Armer JM (2010) Lymphedema beyond breast cancer: a systematic review and meta-analysis of cancer-related secondary lymphedema. Cancer 116:5138-5149.

Corremans R, Adão R, De Keulenaer GW, Leite-Moreira AF, and Brás-Silva C (2019) Update on pathophysiology and preventive strategies of anthracycline-induced cardiotoxicity. Clin Exp Pharmacol Physiol 46:204-215 DOI: 10.1111/1440 1681.13036.

Daeihamed M, Haeri A, and Dadashzadeh S (2015) A simple and sensitive HPLC method for fluorescence quantitation of doxorubicin in micro-volume plasma: applications to pharmacokinetic studies in rats. Iran $J$ Pharm Res 14 (Suppl): 33-42.

Davis MJ, Rahbar E, Gashev AA, Zawieja DC, and Moore JE Jr (2011) Determinants of valve gating in collecting lymphatic vessels from rat mesentery. Am J Physiol Heart Circ Physiol 301:H48-H60.

de Bruijn P, Verweij J, Loos WJ, Kolker HJ, Planting AS, Nooter K, Stoter G, and Sparreboom A (1999) Determination of doxorubicin and doxorubicinol in plasma of cancer patients by high-performance liquid chromatography. Anal Biochem 266:216-221.

Diehl K-H, Hull R, Morton D, Pfister R, Rabemampianina Y, Smith D, Vidal JM, and van de Vorstenbosch C; European Federation of Pharmaceutical Industries Association and European Centre for the Validation of Alternative Methods (2001) A good practice guide to the administration of substances and removal of blood, including routes and volumes. J Appl Toxicol 21:15-23.

Dougherty PJ, Davis MJ, Zawieja DC, and Muthuchamy M (2008) Calcium sensitivity and cooperativity of permeabilized rat mesenteric lymphatics. Am J Physio Regul Integr Comp Physiol 294:R1524-R1532.

FDA Center for Drug Evaluation and Research (2005) Guidance for Industry, Estimating the maximum safe guidance for industry starting dose in initial clinical trials for therapeutics in adult healthy volunteers. Food and Drug Administration, Rockville, MD.

Fedosov I, Aizu Y, Tuchin V, Yokoi N, Nishidate I, Zharov VP, and Galanzha EI (2016) Laser speckles, doppler and imaging techniques for blood and lymph flow monitoring, in Handbook of Optical Biomedical Diagnostics, 2nd ed (Tuchin V ed) pp 299-372, SPIE Press, Bellingham, WA.

Fill M and Copello JA (2002) Ryanodine receptor calcium release channels. Physiol Rev 82:893-922.

Galanzha EI, Shashkov EV, Tuchin VV, and Zharov VP (2008) In vivo multispectral, multiparameter, photoacoustic lymph flow cytometry with natural cell focusing, label-free detection and multicolor nanoparticle probes. Cytometry A 73:884-894

Galanzha EI, Tuchin VV, and Zharov VP (2007a) Advances in small animal mesentery models for in vivo flow cytometry, dynamic microscopy, and drug screening. World J Gastroenterol 13:192-218.

Galanzha EI, Tuchin VV, and Zharov VP (2007b) Optical monitoring of microlymphatic disturbances during experimental lymphedema. Lymphat Res Biol 5:11-27.

Gashev AA (2002) Physiologic aspects of lymphatic contractile function: current perspectives. Ann N Y Acad Sci 979:178-187, discussion 188-196.

Gustafson DL, Rastatter JC, Colombo T, and Long ME (2002) Doxorubicin pharmacokinetics: macromolecule binding, metabolism, and excretion in the context of a physiologic model. J Pharm Sci 91:1488-1501.

Hanna AD, Janczura M, Cho E, Dulhunty AF, and Beard NA (2011) Multiple actions of the anthracycline daunorubicin on cardiac ryanodine receptors. Mol Pharmacol 80:538-549.

Hanna AD, Lam A, Tham S, Dulhunty AF, and Beard NA (2014) Adverse effects of doxorubicin and its metabolic product on cardiac RyR2 and SERCA2A. Mol Pharmacol 86:438-449.

Hansen KC, D'Alessandro A, Clement CC, and Santambrogio L (2015) Lymph formation, composition and circulation: a proteomics perspective. Int Immunol 27: 219-227.

Hasselhof V, Sperling A, Buttler K, Ströbel P, Becker J, Aung T, Felmerer G, and Wilting $J$ (2016) Morphological and molecular characterization of human dermal lymphatic collectors. PLoS One 11:e0164964.

Imtiaz MS, Zhao J, Hosaka K, von der Weid P-Y, Crowe M, and van Helden DF (2007) Pacemaking through $\mathrm{Ca}^{2+}$ stores interacting as coupled oscillators via membrane depolarization. Biophys $J$ 92:3843-3861.

Ji R-C and Kato S (2001) Histochemical analysis of lymphatic endothelial cells in lymphostasis. Microsc Res Tech 55:70-80.

Jo M, Trujillo AN, Yang Y, and Breslin JW (2019) Evidence of functional ryanodine receptors in rat mesenteric collecting lymphatic vessels. Am J Physiol Heart Circu Physiol 317:H561-H574 DOI: 10.1152ajpheart.005642018.

Keung EC, Toll L, Ellis M, and Jensen RA (1991) L-type cardiac calcium channels in doxorubicin cardiomyopathy in rats morphological, biochemical, and functional correlations. J Clin Invest 87:2108-2113. 
Kim S-Y, Kim S-J, Kim B-J, Rah SY, Chung SM, Im M-J, and Kim U-H (2006) Doxorubicin-induced reactive oxygen species generation and intracellular $\mathrm{Ca}^{2+}$ increase are reciprocally modulated in rat cardiomyocytes. Exp Mol Med 38:535-545.

Kong SK and Lee CY (1995) The use of fura 2 for measurement of free calcium concentration. Biochem Educ 23:97-98.

Krause T, Gerbershagen MU, Fiege M, Weisshorn R, and Wappler F (2004) Dantrolene--a review of its pharmacology, therapeutic use and new developments. Anaesthesia 59:364-373.

Lee S, Roizes S, and von der Weid P-Y (2014) Distinct roles of L- and T-type voltagedependent $\mathrm{Ca}^{2+}$ channels in regulation of lymphatic vessel contractile activity. $J$ Physiol 592:5409-5427.

Muthuchamy M, Gashev A, Boswell N, Dawson N, and Zawieja D (2003) Molecular and functional analyses of the contractile apparatus in lymphatic muscle. FASEB J 17 (8):920-922.

Nipper ME and Dixon JB (2011) Engineering the lymphatic system. Cardiovasc Eng Technol 2:296-308.

Norman SA, Localio AR, Kallan MJ, Weber AL, Torpey HAS, Potashnik SL, Miller LT, Fox KR, DeMichele A, and Solin LJ (2010) Risk factors for lymphedema after breast cancer treatment. Cancer Epidemiol Biomarkers Prev 19:2734-2746.

Olson RD, Li X, Palade P, Shadle SE, Mushlin PS, Gambliel HA, Fill M, Boucek RJ Jr and Cusack BJ (2000) Sarcoplasmic reticulum calcium release is stimulated and inhibited by daunorubicin and daunorubicinol. Toxicol Appl Pharmacol 169:168-176.

Pérez-Blanco JS, Fernández de Gatta M, Hernández-Rivas JM, García Sánchez MJ, Sayalero Marinero ML, and González López F (2014) Validation and clinical evaluation of a UHPLC method with fluorescence detector for plasma quantification of doxorubicin and doxorubicinol in haematological patients. J Chromatogr $B$ Analyt Technol Biomed Life Sci 955-956:93-97.

Pessah IN, Durie EL, Schiedt MJ, and Zimanyi I (1990) Anthraquinone-sensitized $\mathrm{Ca}^{2+}$ release channel from rat cardiac sarcoplasmic reticulum: possible receptormediated mechanism of doxorubicin cardiomyopathy. Mol Pharmacol 37:503-514

Rahman A, Carmichael D, Harris M, and Roh JK (1986) Comparative pharmacokinetics of free doxorubicin and doxorubicin entrapped in cardiolipin liposomes Cancer Res 46:2295-2299.

Rahman M and Mohammed S (2015) Breast cancer metastasis and the lymphatic system. Oncol Lett 10:1233-1239.

Reiner AS, Jacks LM, Van Zee KJ, and Panageas KS (2011) A SEER-Medicare population-based study of lymphedema-related claims incidence following breast cancer in men. Breast Cancer Res Treat 130:301-306.

Renu K, V G A, P B TP, and Arunachalam S (2018) Molecular mechanism of doxorubicin-induced cardiomyopathy - an update. Eur J Pharmacol 818:241-253.

Ridner SH, Deng J, Fu MR, Radina E, Thiadens SR, Weiss J, Dietrich MS, Cormier JN, Tuppo CM, and Armer JM (2012) Symptom burden and infection occurrence among individuals with extremity lymphedema. Lymphology 45:113-123.

Rivere AE and Klimberg VS (2018) Lymphedema in the postmastectomy patient: pathophysiology, prevention, and management, in The Breast: Comprehensive Management of Benign and Malignant Diseases, 5th ed (Bland KI, Klimberg VS, Copeland EM, and Gradishar WJ eds) pp 514-530, Elsevier, Philadelphia.

Sarimollaoglu M, Stolarz AJ, Nedosekin DA, Garner BR, Fletcher TW, Galanzha EI, Rusch NJ, and Zharov VP (2018) High-speed microscopy for in vivo monitoring of lymph dynamics. J Biophotonics 11:e201700126 DOI: 10.1002/jbio.201700126.
Scallan JP, Zawieja SD, Castorena-Gonzalez JA, and Davis MJ (2016) Lymphatic pumping: mechanics, mechanisms and malfunction. $J$ Physiol 594:5749-5768.

Schmid-Schönbein GW (1990) Microlymphatics and lymph flow. Physiol Rev 70 987-1028.

Shadle SE, Bammel BP, Cusack BJ, Knighton RA, Olson SJ, Mushlin PS, and Olson RD (2000) Daunorubicin cardiotoxicity: evidence for the importance of the quinone moiety in a free-radical-independent mechanism. Biochem Pharmacol 60: 1435-1444.

Shah C, Arthur D, Riutta J, Whitworth P, and Vicini FA (2012a) Breast-cancer related lymphedema: a review of procedure-specific incidence rates, clinical assessment AIDS, treatment paradigms, and risk reduction. Breast $J$ 18:357-361.

Shah C and Vicini FA (2011) Breast cancer-related arm lymphedema: incidence rates, diagnostic techniques, optimal management and risk reduction strategies. Int J Radiat Oncol Biol Phys 81:907-914.

Shah C, Wilkinson JB, Baschnagel A, Ghilezan M, Riutta J, Dekhne N, Balaraman S, Mitchell C, Wallace M, and Vicini F (2012b) Factors associated with the de velopment of breast cancer-related lymphedema after whole-breast irradiation. Int $J$ Radiat Oncol Biol Phys 83:1095-1100.

Shaitelman SF, Cromwell KD, Rasmussen JC, Stout NL, Armer JM, Lasinski BB, and Cormier JN (2015) Recent progress in the treatment and prevention of cancerrelated lymphedema. CA Cancer J Clin 65:55-81.

Sharma A and Schwartz RA (2012) Stewart-Treves syndrome: pathogenesis and management. J Am Acad Dermatol 67:1342-1348.

Shen B, Ye CL, Ye KH, Zhuang L, and Jiang JH (2009) Doxorubicin-induced vasomotion and $\left[\mathrm{Ca}^{2+}\right]_{\mathrm{i}}$ elevation in vascular smooth muscle cells from C57BL/6 mice. Acta Pharmacol Sin 30:1488-1495.

Söderman M, Thomsen JB, and Sørensen JA (2016) Complications following inguinal and ilioinguinal lymphadenectomies: a meta-analysis. J Plast Surg Hand Surg $\mathbf{5 0}$ $315-320$

Souza-Smith FM, Kurtz KM, and Breslin JW (2011) Measurement of cytosolic $\mathrm{Ca}^{2+}$ in isolated contractile lymphatics. J Vis Exp (58) DOI: 10.3791/3438.

Tummel E, Ochoa D, Korourian S, Betzold R, Adkins L, McCarthy M, Hung S, Kalkwarf K, Gallagher K, Lee JY, et al. (2017) Does axillary reverse mapping prevent lymphedema after lymphadenectomy? Ann Surg 265:987-992.

Turner PV, Brabb T, Pekow C, and Vasbinder MA (2011) Administration of substances to laboratory animals: routes of administration and factors to consider. $J$ Am Assoc Lab Anim Sci 50:600-613.

Wei G, Xiao S, Si D, and Liu C (2008) Improved HPLC method for doxorubicin quantification in rat plasma to study the pharmacokinetics of micelle-encapsulated and liposome-encapsulated doxorubicin formulations. Biomed Chromatogr 22: 1252-1258

Zawieja DC (2009) Contractile physiology of lymphatics. Lymphat Res Biol 7:87-96. Zhao J and van Helden DF (2003) ET-1-associated vasomotion and vasospasm in lymphatic vessels of the guinea-pig mesentery. Br J Pharmacol 140:1399-1413.

Address correspondence to: Dr. Amanda J. Stolarz, Department of Pharmaceutical Sciences, University of Arkansas for Medical Sciences, 4301 W. Markham Street, \#622, Little Rock, AR 72205. E-mail: ajstolarz@uams.edu 